\title{
Oferta y demanda y el ciclo económico: una interpretación de la situación económica actual
}

\author{
ANTONIO GARCÍA LIZANA \\ Departamento de Economía Aplicada (Política Económica) \\ UNIVERSIDAD DE MÁLAGA, ESPAÑA \\ e-mail: aglizana@uma.es
}

\begin{abstract}
RESUMEN
Tomando como punto de partida las dificultades económicas actuales, se pretende, siguiendo el modelo cíclico de Ibn Jaldún, una aproximación a las oscilaciones de la actividad económica teniendo en cuenta simultáneamente los lados de la oferta y de la demanda, entendiendo que el protagonismo de uno y otro lado puede modificarse en el tiempo, o que los dos pueden actuar simultáneamente, como sería el caso en la situación económica actual a juzgar por los síntomas observados. Asimismo, se llama la atención sobre la complejidad existente en la práctica, si se tiene en cuenta la riqueza de las motivaciones humanas, frente al carácter unidimensional del homo oeconomicus smithiano, a partir del cual se han elaborado nuestras concepciones económicas.
\end{abstract}

Palabras clave: Oferta y demanda, ciclos económicos, motivaciones humanas, Ibn Jaldún.

\section{Supply and Demand Sides and the Economic Cycle: An Interpretation of the Current Situation}

\begin{abstract}
Starting from the current economic difficulties, we will try to increase our knowledge of economic cycle with the help of Ibn Khaldûn Cyclical Model, considering simultaneously the eventual shocks of demand and supply sides. Both of them may influence on the oscillatory movements of economic activity, separately (with different grades of emphasize each one, depending on the moment) or simultaneously. According to the observed symptoms, we think the last option should be the best explanation nowadays. We also have to remark the real complexity of economic functioning, having in mind the variety of human motivations versus the one-dimensional character of Smith's homo oeconomicus, which is in the basis of our conventional economic conceptions.
\end{abstract}

Keywords: Supply and Demand, Economic Cycles, Human Motivations, Ibn Khaldûn.

Clasificación JEL: B11, B29, B31, E10, E39. 


\section{INTRODUCCIÓN}

Desde que en 2007 la economía mundial, en general, y la española, en concreto, comenzaron a manifestar los síntomas de un proceso que las está llevando a altos niveles de deterioro, aun cuando los efectos no sean los mismos en todos los países, hay un aspecto que parece pasar desapercibido: el hecho de haber coexistido, en diferentes momentos del tiempo, junto con un paro en aumento y un crecimiento con serias dificultades, ciertas tasas de inflación, episodios de deflación y situaciones de estabilidad de precios más o menos acusada. Lo que, evidentemente, contrasta con los dos grandes episodios históricos del siglo XX de deterioro económico generalizado que siguieron, respectivamente, a las crisis de 1929 y 1973. El primero caracterizado por la coexistencia de paro y deflación; y el segundo por el desempleo y la inflación. Lo que fue atribuido, respectivamente, a problemas existentes en el lado de la demanda, en un caso; y en el de la oferta en el otro. ¿Cuál es, precisamente, la explicación en la actualidad?

Los analistas y decisores públicos, lejos de abordar el conjunto de acontecimientos bajo una perspectiva unitaria, han prestado su atención a aspectos puntuales, aunque ciertamente llamativos, que, previsiblemente, sólo constituyen epifenómenos producto de un comportamiento económico general distorsionado, cuya naturaleza profunda convendría estudiar. Lo que se pretende en este artículo es contribuir a iluminar el panorama enunciado, aproximándonos a la realidad con el propósito de superar el puro análisis fenomenológico, mediante la indagación orientada a comprender los mecanismos que explican el funcionamiento económico en su totalidad, y, en concreto, sus oscilaciones, en términos de precios, empleo y producción, poniendo de relieve la importancia de aprehender de manera simultánea el impacto de comportamientos provenientes tanto del lado de la oferta como de la demanda, y que afectan al proceso de toma de decisiones por parte de los agentes económicos y sociales y, a través del mismo, al funcionamiento económico general.

Si nuestro trabajo da sus frutos, debe permitirnos identificar patrones significativos de conducta, para poder predecir las secuencias de evolución inmediatas y poder influirlas, manipulando y rectificando las variables sobre las que podemos ejercer algún control, de modo que situaciones negativas como la actual, puedan repararse; e, incluso, prevenirse.

En nuestra ayuda, para tal tarea, podemos contar con la aportación realizada por Ibn Jaldún ${ }^{1}$, quien, a pesar de la época en que trabajó (siglo XIV-XV), tuvo la habilidad de leer simultáneamente en el lado de la oferta y en el lado de la demanda, observando el modo en el que, según las circunstancias, las oportunidades y dificultades estaban en uno u otro, o, incluso, simultáneamente en los dos. Hasta tal punto es así, que ha sido considerado precursor tanto de Keynes como de los economistas del lado de la oferta, quienes invocaron a partir de los últimos setenta su autoridad (ver Laffer y Seymour, coord, 1979). La interacción de ambos lados se

\footnotetext{
${ }^{1}$ Para un mejor conocimiento de dicho autor puede consultarse Estapé, 1993 y 2000.
} 
resuelve en alimentar unos determinados patrones evolutivos de la sociedad, en los que juega lo económico un papel decisivo. Por esta razón, Ibn Jaldún ha sido considerado, igualmente, un adelantado en el estudio de los ciclos económicos, al explicar la secuencia temporal de periodos de auge, decadencia y recuperación. Sus enseñanzas pueden, por lo tanto, sernos de utilidad para afrontar los problemas de hoy. Máxime si tenemos en cuenta la idea que mantuvo: conocidas las leyes que rigen la sociedad, estaremos en condiciones de discernir la verdad de nuestras investigaciones sobre los hechos ocurridos; pero también de prever los cursos futuros del devenir humano e influir anticipadamente sobre los mismos, como parte de la labor de gobierno (ver, p. ej., Ibn Jaldún [1377] 1977, 100, 134). También en esto es un precursor de la Ciencia Económica moderna, en general, y de la Economía Aplicada, en concreto.

Tras presentar de manera sucinta la situación actual y sus evolución reciente, con el fin de enmarcar mejor la problemática considerada, y revisar, a continuación, el modelo cíclico de Ibn Jaldún, nos ocuparemos de analizar desde esta perspectiva dicha situación, completando y adaptando aquel modelo, para finalizar con unas conclusiones generales que permitan sintetizar la utilidad práctica de la investigación efectuada, dentro de la unidad temática del presente número de Estudios de Economía Aplicada.

Conviene advertir, con todo, que no se pretende, en absoluto, dar por cerrado un tema tan ambicioso como el aquí planteado; y que sólo se busca ofrecer algunos criterios que faciliten la incorporación empírica de nuevas variables y nuevas relaciones en los modelos que pretenden explicar el funcionamiento económico, en general, y el comportamiento cíclico, en concreto.

\section{LA SITUACIÓN ECONÓMICA ACTUAL Y SU EVOLUCIÓN RECIENTE}

Cuando el 23 de junio de 2008, el presidente de Gobierno de España, José Luis Rodríguez Zapatero, reconoció por primera vez las dificultades de la economía española, asumiendo que ésta "atraviesa un periodo difícil que afecta a las economías domésticas y ensombrece las percepciones ciudadanas" (ver El País, 24 de junio de 2008, p. 25), los datos que estaba manejando entre el primer trimestre de 2007 y la misma fecha de 2008 eran los siguientes: caída continuada de la tasa del crecimiento del PIB desde el 4,1\% al 2,7\%; aumento de la tasa de paro desde el 8,5\% al 9,6\%; aumento de la tasa de inflación del 4,3\% al 4,6\%. Dichos datos ponen sobre aviso acerca de la existencia de un problema en el lado de la oferta, al presentarse un deterioro del crecimiento y el empleo al mismo tiempo que crecen los precios. Situación que no era de extrañar, si se tiene en cuenta la subida que venían experimentando los costes de la energía y la caída paulatina de la productividad.

Sin embargo, las principales recetas adoptadas en ese momento por el Ejecutivo presidido por Zapatero estaban orientadas hacia el lado de la demanda, disminu- 
yendo el gasto ${ }^{2}$ a través de la reducción de la oferta de empleo público en un $70 \%$, el recorte del gasto corriente y la congelación de los sueldos de los altos cargos; pretendiendo, además, que el resto de las administraciones públicas siguieran el ejemplo. Al mismo tiempo, anunciaba el inicio de la privatización parcial de los aeropuertos, lo que también puede interpretarse como un reforzamiento de la misma línea política.

Al proceder así parece obvio pensar que el Gobierno pretendía atacar la inflación, olvidando los problemas del crecimiento y el empleo; lo que resulta paradójico, en principio, para un Gobierno socialista. La explicación razonable de tal comportamiento estaría en atribuir a la inflación las dificultades existentes en los otros dos frentes. Pero si el origen de la inflación se encontraba en el lado de la oferta, las consecuencias de las medidas adoptadas para reducir la demanda sólo podrían provocar un mayor deterioro en la producción y el empleo, fracasando en el frente de los precios.

Pero no era sólo el Gobierno español el que estaba intentando atajar los efectos de la inflación por el lado de la demanda. Los principales bancos centrales adoptaban una posición similar, tratando de contrarrestar las tensiones inflacionistas mediante el aumento de los tipos de interés de referencia. Sin advertir que estaban contribuyendo, con tal política, a endurecer las condiciones financieras que debían asumir las empresas, alimentando de este modo, aún más, por el lado de la oferta la inflación.

La verdad es que todo ello resulta asombroso, después de lo supuestamente aprendido en los años setenta y ochenta del pasado siglo, cuando los modelos económicos vigentes eran deudores aún (con todas las matizaciones que se quiera) del trabajo de Keynes, cincuenta años atrás, ante otra situación igualmente difícil, surgida de la crisis de 1929. Ambas situaciones (la de los treinta y la de los setenta), aunque diferentes en lo que al comportamiento de los precios se refiere (inflación en los setenta-ochenta; deflación en los treinta), compartían diversos rasgos, como haber sido precedidas por periodos de prosperidad (los felices veinte y los prodigiosos sesenta) y mostrar un elevado deterioro económico, incluyendo el cierre de empresas, las caídas de la producción y el aumento del paro.

Keynes se había propuesto descubrir, precisamente, las condiciones que explican el empleo para responder a los desafíos del momento. Tras afirmar que su volumen está determinado por el punto de intersección de las funciones de oferta agregada y demanda agregada, y dado que la primera era suficientemente conocida por los economistas de su tiempo (Keynes [1936] 1983, 89), decidió ocuparse de la segunda, asignándole un papel central. Aquí se encuentra una de sus grandes innovaciones: el papel activo de la demanda, provocando un giro copernicano con respecto a sus contemporáneos, para quienes la clave estaba en la oferta. El éxito de Keynes fue tal que los economistas, convertidos al nuevo paradigma, olvidaron la interpretación clásica, de tal modo que cuando se presentaron los problemas justo en el lado de la

\footnotetext{
${ }^{2}$ No obstante, también se incluía una línea de crédito del ICO para PYMES y viviendas protegidas.
} 
oferta, en los setenta, no podían entender lo que pasaba. Exactamente lo mismo que ocurrió (aunque a la inversa) en los treinta, concluyendo en ambas ocasiones en análogo desprestigio de la Ciencia Económica (v. Keynes [1936] 1983, xxi; y Ball 1980, 56). Sólo cuando comenzó a comprenderse la nueva situación, se recuperó la visión de una oferta activa, de la mano de la que entonces se denominó "Economía del lado de la oferta". Ello, unido a la desconfianza despertada hacia el sector público, por su falta de capacidad para resolver diligentemente los problemas de la economía, hicieron perder luminosidad a la estrella de Keynes.

Parece, a la vista de lo señalado, como si los economistas fuéramos incapaces de percibir el problema económico de una manera integral, centrándonos (dependiendo de la escuela de pensamiento o del momento histórico) o bien en el lado de la demanda o bien en el lado de la oferta. Y las cosas no han parecido cambiar. A raíz de los problemas sobrevenidos en la primera década del siglo XXI, se ha despertado, de nuevo, la memoria de Keynes, tras un largo periodo de confianza en los ajustes automáticos y la racionalidad de los mercados (ver Arias, 2009, p. 34); concediendo nuevas oportunidades a la gestión de la demanda (con independencia de que este último aspecto fuera o no apropiado).

¿Pero qué pensar ahora, en 2010, cuando nos enfrentamos no a una situación de deflación con paro, similar a la de los treinta; pero tampoco a un episodio de estanflación, como en los setenta y ochenta, o en la primavera de 2008? Obviamente hay paro creciente y dificultades muy serias que limitan y deprimen el crecimiento de la producción, hasta hacerlo en ocasiones negativo; pero el comportamiento de los precios podría calificarse de estable. Pequeñas oscilaciones al alza o a la baja, que no definen con claridad ninguna tendencia consistente en uno u otro sentido. Aun cuando clamen angustiados algunos políticos y economistas temblando ante una eventual deflación cuando los precios bajan durante un breve lapso de tiempo; y respiren aliviados cuando parece invertirse la tendencia.

Economistas y políticos, lejos de admitir, como en los episodios anteriores, su incapacidad para atajar la situación de fondo de la economía con los modos conocidos y ponerle remedio, se han quedado observando ciertos fenómenos que les ha parecido o más llamativos o más preocupantes, pero aparentemente más fáciles de resolver aplicando medidas simplistas y directas, como los problemas de determinadas instituciones financieras, primero, o los abultados déficits públicos, después, sin considerar las eventuales relaciones con el comportamiento económico general, o los patrones de fondo que explican la marcha total de los acontecimientos y su concreción sintomática a través de determinadas manifestaciones más fáciles de observar.

En el caso del déficit público, en buena parte mera consecuencia de las dificultades económicas contextuales que reducen la recaudación fiscal y aumentan los gastos de protección social, se pretende reducir haciendo abstracción de aquellas, intentando manejar autónomamente los ingresos, mediante el aumento de los impuestos, y los gastos públicos, reduciendo de modo voluntarista determinadas partidas presupuestarias, apelando a la solidaridad y al sacrificio colectivo, sin querer advertir la conexión de las cuentas públicas con las privadas, o tomar en cuenta los efectos sobre unas y otras de los movimientos experimentados por oferta o la de- 
manda. O, a tenor de los hechos percibidos, y para mejor explicar los síntomas citados, de los movimientos experimentados simultáneamente por la oferta y por la demanda, de modo que las caídas del empleo y de la producción vendrían explicadas por las dificultades en uno y otro lado que se refuerzan; mientras que la aparente estabilidad de los precios sería la percepción superficial de impactos dispares sobre los mismos originados igualmente en ambos lados, que se contrarrestan.

Tan complicada situación podría estar, igualmente, detrás de los brotes verdes tantas veces percibidos y abortados; en realidad, efectos reflejos de los comportamientos poco armónicos de las variables situadas en ambos lados, que ofrecen resultados estadísticos volátiles, de carácter dispar. La situación resulta, sin embargo, desmoralizante para la población, que ve mermado su bienestar y sufre, al menos de momento, estoicamente la acumulación de medidas de variado signos que los poderes públicos improvisan, sin haber realizado un diagnóstico preciso de qué es lo que en realidad está pasando y de las causas que sería preciso atacar. Que el desprestigio de la clase política vaya en aumento no es, dadas las circunstancias, de extrañar. Para fortuna de los economistas, cuya responsabilidad en el caso aparece oculta por la de los dirigentes, políticos o sindicales, a diferencia de los dos episodios citados anteriores durante el siglo XX.

Sin embargo, parafraseando a Keynes, cuando intentaba trazar el camino hacia la prosperidad en plena Gran Depresión (ver Keynes [1933] 1973, p. 89 y 102), habría que pensar que si nuestras dificultades fueran debidas a la aparición súbita de hambrunas a escala planetaria, o a cataclismos geológicos, o a guerras; si nos faltaran bienes materiales y los recursos para producirlos, no podríamos encontrar el camino para la recuperación a menos que nos esforzáramos entre todos trabajando con mayor dureza, padeciendo abstinencia y sacrificios o reduciendo nuestros ingresos y nuestros gastos de modo solidario. Pero ello, lejos de ser un medio que permita reducir el paro y aumentar la riqueza colectiva, es, más bien, un modo de distribuir solidaria y equitativamente el paro y la pobreza, a costa de aumentarlos algo (o mucho) más.

$\mathrm{Si}$, por otra parte, la situación que padecemos fuera el resultado de inexorables vaivenes cíclicos característicos del comportamiento económico, tal vez la mejor solución podría ser esperar, sencillamente, el paso del tiempo, compartiendo solidariamente las dificultades, porque el juego de las acciones y reacciones económicas nos devolvería tarde o temprano a las playas de la estabilidad y el bienestar. Pero de las dificultades económicas no siempre es factible salir, y la experiencia internacional a lo largo del siglo XX da buenas muestras de ello. El hundimiento de la Unión Soviética o la década pérdida de Latinoamérica tienen mucho que ver con comportamientos "cíclicos" no resueltos favorablemente.

\section{EL MODELO DE IBN JALDÚN: UNA VISIÓN ANALÍTICA}

Con el propósito de comprender adecuadamente el modelo de Ibn Jaldún y situarlo en relación con las aportaciones posteriores de la Ciencia Económica, conviene, 
antes de la descripción del mismo y de su aplicación a la situación actual, examinar el marco donde sitúa su tratamiento del problema económico, los presupuestos de partida y los rasgos básicos que lo caracterizan, lo que nos ayudará a valorarlo en toda su extensión. A todo ello nos referimos a continuación.

\subsection{El marco de trabajo}

Antes de entrar en el detalle de su aportación, conviene advertir que Ibn Jaldún adoptó una perspectiva más amplia que la estrictamente económica. A él no le preocupa el suceso económico en sí mismo. Le preocupa la dinámica social. Qué es lo que hace que las sociedades cambien. Cuál es la razón por la que los imperios surgen, se expanden y fenecen. A qué se deben los cambios en el gobierno de las sociedades. Qué es lo que explica la decadencia política y militar o el progreso de la tecnología... Y al investigar sobre todo ello descubre la economía interactuando con los demás componentes de la vida social, sometida a oscilaciones temporales de auges y depresiones.

Dicha preocupación hay que entenderla conectada con su condición de historiador. En cuanto tal, le preocupa la certeza del dato recogido. En su afán por discernir la verdad del error (Ibn Jaldún [1377] 1977, 142), plantea la importancia del método. Como parte de éste, adoptando un enfoque racionalista, defiende que la validez del dato debe ser establecida por su concordancia con la naturaleza de la sociedad humana y las leyes que la explican ${ }^{3}$. De ahí la necesidad del estudio de la sociedad, en cuanto tal, y de las condiciones de la misma. Para ello propone una ciencia nueva, no abordada por nadie antes de él ${ }^{4}$, con el propósito de dar respuesta a preguntas como las arriba planteadas, como piedra de toque para contrastar la validez de las aportaciones de la ciencia histórica. Por tal motivo, el primer libro de su Historia Universal, y antes de ocuparse de ésta, lo dedica, precisamente, a tal ciencia nueva, cuyo objeto es la sociedad, entre cuyas manifestaciones aparece la economía ${ }^{5}$.

${ }^{3}$ Como el premio Nobel de Economía M. Friedman, seiscientos años después, Ibn Jaldún viene a decir que "si los hechos no se corresponden con la teoría, hay que desconfiar de los hechos". De ahí que Ibn Jaldún aplique continuamente sus deducciones teóricas a casos reales para confirmar sus hallazgos o mejorar la comprensión de dichos ejemplos históricos.

${ }^{4}$ Resulta interesante comprobar que su estilo responde al de las revoluciones científicas, según la propuesta de Khun, resultando extremadamente curiosas, p. ej., las similitudes que se detectan entre el Prefacio del Ibn Jaldún a su Discurso de la Historia Universal y el de John M. Keynes a su Teoría General. Así, Jaldún señala que hubo de despertar a su intelecto de su somnolencia y pereza, y realizar un regateo consigo mismo para decidirse a escribir su obra; Keynes señala que la escritura de su obra fue una lucha de liberación de las ideas en las que se había formado (ver García Lizana y Chamizo 2002).

${ }^{5}$ Conviene advertir que, posiblemente, la novedad de Ibn Jaldún sea la conciencia de estar produciendo tal ciencia de la sociedad, y abordar sistemáticamente su estudio. Pues también los escolásticos "intentaron crear una ciencia social con alcances muy amplios (una teoría global que interpretara los fenómenos sociales desde los diversos puntos de vista, incluyendo también su funcionamiento). 
A lo largo del libro, al que citaremos en lo que sigue como "La sociedad humana", , va deduciendo su modelo de desarrollo social que sitúa en lo económico uno de los hilos conductores del progreso humano, constituyendo el tratamiento de los ciclos (aunque no utilice este término) una línea permanente de atención.

\subsection{Presupuestos de partida}

El punto de partida del modelo se encuentra en la aceptación de un principio general: todas las cosas existen y actúan conforme a su naturaleza, según las leyes ${ }^{7}$ que rigen el Universo. Por tanto, si pretendemos conocer el funcionamiento de las sociedades humanas, es preciso partir del conocimiento de la naturaleza humana, deduciendo a partir de la misma cuáles son las leyes de acuerdo con las cuales dichas sociedades se organizan y desarrollan, lo que nos debe permitir no sólo validar las afirmaciones de los historiadores, sino anticiparnos al futuro y orientar el gobierno de los pueblos. En realidad, tal posicionamiento no es muy diferente del mantenido por los autores que han hecho avanzar la Ciencia Económica a partir de los siglos XVIII y XIX.

Como tales autores, entiende que la naturaleza de los seres humanos se caracteriza por la existencia de múltiples necesidades que exigen ser satisfechas y recursos limitados para afrontarlas. Sin embargo, Ibn Jaldún añade la nota de la insaciabilidad, ya que las mismas no se agotan; se renuevan sin cesar: satisfecha una, aparecen otras, en un proceso de complejidad creciente, aspecto clave para explicar el mantenimiento y desarrollo del proceso económico.

Ahora bien, hay una diferencia aún más decisiva entre Ibn Jaldún y el común de dichos autores. Mientras que la Ciencia Económica moderna se ha organizado partiendo del supuesto planteado por Smith y la Escuela Clásica del homo oeconomicus, es decir, de un ser humano individual movido por el egoísmo, de acuerdo con lo cual intenta optimizar la satisfacción de sus necesidades mediante la asignación más apropiada de los recursos escasos, y de ahí extraen sus conclusiones acerca del funcionamiento de la vida económica, Ibn Jaldún considera un ser humano mucho más complejo, que posee diversas inclinaciones. En primer lugar, comparte la idea de la inclinación individual hacia la satisfacción de las propias necesidades. Pero, de forma inmediata, deduce de aquí el carácter e inclinación social, ya que las limi-

Dentro de estas condiciones no era la economía un aspecto al que dedicaran particular importancia ni una materia independiente de las demás" (Iizuka s/f, p. 45, citando a Schumpeter 1954, 118).

${ }^{6}$ El título, en realidad, es más extenso, teniendo un carácter descriptivo: "De la sociedad humana y de los fenómenos que en ella se presentan, tales como la vida nómada, la vida sedentaria, la dominación, la adquisición, los medios de ganar la subsistencia, los oficios, las ciencias y las artes. Indicación de las causas que conducen a esos resultados". Lamentablemente, se ha dado por ocultarlo tras la etiqueta "Introducción" o "Prolegómenos" a su Historia Universal, algo que, en puridad, sólo corresponde al texto que precede al propio libro. Éste es bastante más que una mera introducción histórica.

${ }^{7}$ Ibn Jaldún considera que tales leyes tienen un origen divino. Pero ello no altera el fondo del planteamiento y la línea de argumentación recogida en el texto. 
taciones personales sólo pueden compensarse mediante la interacción con otros individuos, explicando las ventajas que se siguen de la división de trabajo y el intercambio, buscando maximizar la utilidad personal. Ahora bien, junto al intercambio mercantil, introduce también la idea de ayuda mutua, favoreciéndose de ambos modos la multiplicación de recursos con que satisfacer aquellas múltiples y renovadas necesidades.

El ser humano presenta, además, un carácter ambivalente: abierto al bien y al mal, con inclinaciones inherentes a su condición animal, como la agresividad o las pasiones, que llevan a distorsionar los intereses personales hasta el extremo, generando una tensión permanente entre ambas tendencias, que condicionan la dinámica social. La sociedad se ve amenazada, por tanto. Internamente, por sus propios componentes; externamente, por otros grupos. De ahí la autoridad, para garantizar el orden interno y la defensa frente a extraños.

Tanto la colaboración como el ejercicio de la autoridad encuentran un apoyo poderoso en los afectos generados por la vida en común, que favorecen la unión de ánimos, la identificación grupal y la solidaridad, garantizando la cohesión, la ayuda mutua y el servicio desinteresado. En estos vínculos solidarios de identificación social (asabiya) va a situar Ibn Jaldún una clave fundamental para explicar el progreso social y el comportamiento cíclico.

Hoy, cuando tanta importancia se da a las iniciativas no lucrativas (ver Herrera y Castón, 2003; Monzón, coord., 2008), no puede olvidarse la eventual incidencia económica de las actitudes solidarias y cooperativas, más allá del egoísmo como motor económico. Como mínimo, en las actuales circunstancias, ante los aumentos del desempleo y las tasas de pobreza, están contribuyendo a mantener ciertos niveles de protección social y, por tanto, de consumo, con costes relativamente más reducidos que los correspondientes al sector público y, desde luego, el privado lucrativo. $\mathrm{O}$, en el extremo opuesto, ante la responsabilidad atribuida a la codicia como desencadenante, en última instancia, de la crisis financiera que ha desembocado en los actuales problemas económicos (ver, p. ej., Trías de Bes 2009), tampoco puede perderse de vista la incidencia negativa de los "espíritus animales" (por utilizar la conocida expresión de Keynes) presentes en el ánimo del ser humano.

\subsection{Rasgos básicos del modelo}

Partiendo de esa naturaleza humana compleja tal como ha sido identificada, deduce Ibn Jaldún su modelo de dinámica social. Un modelo que se caracteriza por los rasgos siguientes: 1) No se trata de un modelo mecanicista, determinista y uniforme, sino de un proceso al que tienden las colectividades humanas, admitiendo caminos alternativos, variantes y excepciones, a pesar de que algunos autores, como Cruz Hernández o Grice-Hutchinson, planteen una interpretación diferente; 2) A diferencia de las escuelas económicas modernas que ponen el acento o bien en el lado de la oferta o bien en el de la demanda, Ibn Jaldún considera ambos lados, otorgando mayor protagonismo a uno o a otro, o, incluso, a ambos simultáneamen- 
te, según las circunstancias; 3 ) Considera el funcionamiento económico integrado en el proceso social general, pero no haciendo depender exclusivamente a uno del otro (lo social de lo económico, como podría argumentarse desde un enfoque marxista, o a la inversa, bajo una interpretación institucionalista), sino influyéndose recíprocamente, aunque con mayor peso en una u otra dirección según la situación concreta y la fase del proceso evolutivo; 4) Algo análogo puede decirse del comportamiento de los avances tecnológicos, integrados dentro del propio proceso económico, interactuando de un modo u otro según corresponda (lo que, salvando distancias, lo acerca a las modernas teorías del crecimiento endógeno); 5) Igualmente, el comportamiento no sólo de los agentes privados, sino también de los públicos, está integrado en el movimiento económico y social general, dependiendo de las fases en que éste se encuentre e influyendo en las características de las mismas; 6) La visión cíclica del comportamiento económico está relacionada con el tipo de decisiones que los diversos agentes toman en cada momento, las cuales puede preverse de antemano, en función del conocimiento de la naturaleza humana y de las condiciones sociales y económicas existentes.

\subsection{Descripción del modelo}

Conviene advertir, ante todo, que el análisis del comportamiento cíclico de la economía no es un añadido a su trabajo intelectual, sino que está en el propio núcleo de éste, al detectar que el funcionamiento económico se ve, a lo largo del tiempo, sometido a tales fluctuaciones. Simplificando la descripción realizada a lo largo de los diversos capítulos de La sociedad humana, el punto de partida se encuentra en la fase de expansión, a impulso, como en los modelos clásicos del ciclo económico, fundamentalmente, de la oferta (aunque no necesariamente por la presencia de innovaciones), estimulada por la colaboración entre los sujetos, tanto mediante la ayuda mutua como el intercambio, que favorecen la división de trabajo y el incremento consiguiente de la productividad. Los mayores recursos obtenidos estimulan la demanda, al tiempo que favorecen el crecimiento de la población (incluida la inmigración), con su doble repercusión tanto en términos de oferta como de demanda. La reiteración de la actividad productiva para satisfacer la demanda favorece la especialización profesional y el avance tecnológico, lo que consolida el proceso expansivo. Los mayores ingresos de la población repercuten, no sólo, en una mayor capacidad de gasto privado, sino también en mayor recaudación fiscal, favoreciendo el crecimiento del gasto público, el cual se convierte, a su vez, en el principal motor de la economía, dada su magnitud. Y ello tanto en términos de demanda, como en función de los impactos producidos en el lado de la oferta, al favorecer el desarrollo del capital físico social, el capital humano y la tecnología, así como los aumentos de productividad inducidos por todo ello.

Sin embargo, la prosperidad general favorece la inclinación a consumos cada vez más extensos y sofisticados, al lujo, los gastos superfluos, la codicia..., relajando los valores éticos y estimulando la corrupción y el fraude como modos fáci- 
les de conseguir recursos para enriquecerse y atender las tendencias crecientes del gasto, la acumulación y la ostentación; todo lo cual se traduce en una caída de la productividad y en un debilitamiento de la cohesión social. Ello afecta tanto al sector privado como al público, cuyos responsables (miembros de la misma sociedad y seres humanos con las mismas pulsiones, en definitiva) también se ven aquejados de las mismas inclinaciones. Pero con una mayor capacidad para condicionar el proceso colectivo. Para aumentar los ingresos desde el sector público se recurre a incrementar la presión fiscal, confiscar propiedades y realizar actividades productivas de índole mercantil, todo lo cual desmotiva al sector privado, encarece los precios, relajándose en consecuencia la demanda..., llevando a la sociedad hacia el empobrecimiento paulatino y la recesión... Tales circunstancias se convierten en nuevos alicientes para la corrupción, la evasión fiscal..., como formas de medrar o simplemente sobrevivir en un medio hostil, al tiempo que se deteriora la credibilidad y legitimidad de la autoridad, aumentan las tensiones sociales, etc. La tentación intervencionista se ve, ante tal panorama, reforzada, con el propósito de controlar más intensamente la situación. Pero ello no hará sino agravar aún más las cosas, reforzando el rechazo y la resistencia de unos, desmotivando la iniciativa de todos y recortando aún más los incentivos para mantener la capacidad productiva general.

La recuperación no es contemplada como una salida necesaria de la recesión, que podría verse prolongada en el tiempo provocando una auténtica involución de las sociedades. Sólo una modificación de los valores imperantes permitiría, para Ibn Jaldún, recuperar la situación, lo cual suele requerir el cambio del grupo dirigente, de manera que se recupere la credibilidad de las instituciones, la ilusión de la sociedad, el sentimiento de unidad y se pueda adoptar una línea política diferente.

\section{LA SITUACIÓN ACTUAL FRENTE AL MODELO DE IBN JALDÚN}

Si tenemos en cuenta que el propósito de Ibn Jaldún no es estrictamente económico y que le preocupa mucho más el largo plazo que las preocupaciones inmediatas, pretendiendo, además, dotarlo de una validez universal y permanente, puede, fácilmente, calibrarse que debe dejar al margen numerosos aspectos puntuales que, en una coyuntura concreta, pueden presentarse. Pero, en todo caso, permite al menos orientar el trabajo de indagación, a la búsqueda de elementos explicativos.

De todos modos, frente a las circunstancias actuales, y, posiblemente, con mayor nitidez que en otras, su llamada de atención sobre los efectos del consumismo desbocado y la codicia, además de su insistencia en los problemas planteados tanto en el lado de la oferta como en el de la demanda, puede servir de ayuda para orientarnos en la interpretación de lo que está ocurriendo, para modelizar adecuadamente la evolución de los acontecimientos dentro del ciclo económico, y, sobre todo, encontrar soluciones eficaces, eficientes y efectivas ${ }^{8}$. Conviene advertir, no obstan-

\footnotetext{
${ }^{8}$ Sobre el concepto de efectividad puede verse García Lizana y Moreno (2008).
} 
te, que el análisis de Ibn Jaldún se refiere a sociedades particulares, sometidas a sus propios ritmos, en contacto con otras que atraviesan fases distintas. La diferencia fundamental es que hoy todos los países (al menos los más relevantes) son parte de una misma sociedad global, por lo que su modelo debe proyectarse sobre tal escenario ampliado.

De acuerdo con ello, habrá que convenir, ciertamente, que la larga etapa de prosperidad atravesada en los comienzos del siglo XXI ha estimulado una expansión del gasto (favorecido por la existencia de amplias facilidades crediticias) que ha alcanzado tanto al sector privado como al público, y no sólo en el mundo occidental; también en las conocidas como economías emergentes. Lo cual, al mismo tiempo, despertó la codicia de muchos ("un insaciable sentimiento de codicia", en palabras de Tamames, 2009, p. 28), que creyeron encontrar el caldo de cultivo idóneo para sus pretensiones lucrativas tanto en las posibilidades abiertas en los mercados inmobiliarios como financieros (o en la peculiar combinación de ambos, la "invención" de las hipotecas titulizadas, en palabras de Skidelsky, 2009). Tal vez la exuberancia manifiesta de tal situación hizo perder de vista a los Gobiernos y a los Bancos Centrales la amenaza presente en el lado de la oferta. En efecto, aun cuando estuviera estimulado por la expansión de la demanda internacional (sin descartar la influencia de los especuladores, ante la caída de los precios de la vivienda y la depreciación del dólar, según apunta Naudé, 2010, p. 6), el hecho cierto era la presión que representaban los incrementos del precio del petróleo, de otros productos energéticos, materias primas, etc. (ver Tamames, 2009, p. 26), introduciendo tensiones inflacionistas evidentes en la función de costes. Ello, unido a las caídas de la productividad como consecuencia de las orientaciones que estaba siguiendo la actividad económica (aunque en algunos países, como España, con mayor incidencia que en otros), ofrecía un horizonte poco alentador, encontrándose las dificultades fundamentales, a la altura de la primavera de 2008, precisamente en el lado de la oferta. Pero, a pesar de tales síntomas, que debían haber puesto sobre aviso a los responsables políticos y económicos de la naturaleza de los problemas, todos contribuyeron a deprimir de forma directa la demanda, sin atajar los problemas de la oferta (por tanto, sin resolver la situación), ni advertir las consecuencias que de ello podían seguirse en presencia de la peligrosa situación de los mercados financieros, alterados, entre otras razones, por la codicia de unos y el afán de gasto por encima de las posibilidades de otros, que había venido caracterizando la etapa inmediatamente anterior, y que había terminado maniatando a empresas, familias y gobiernos a la servidumbre del crédito.

En efecto, los reducidos tipos de interés durante los años anteriores habían ido propiciando un aumento de los créditos concedidos tanto a las economías domésticas como al sector público, aplicando, además, los bancos prácticas poco ortodoxas en cuanto a valoración de riesgos, garantías, etc. En el caso de las familias, y no vale la pena insistir en ello por ser harto conocido, el endeudamiento alcanzó a un gran número de hogares caracterizados por su baja capacidad adquisitiva y su escasa solvencia, distribuyéndose los riesgos anexos a tales créditos de forma generali- 
zada en todo el planeta, merced a los mecanismos de titulización y de incorporación de tales deudas en los fondos de riesgo, vendidos por doquier.

El aumento del coste del crédito (como consecuencia, entre otros motivos, de una demanda crediticia persistente), alimentado, además, con las miopes políticas de los bancos centrales intentando controlar una inflación de oferta con medidas diseñadas para actuar sobre la demanda, no podía sino dificultar la situación de las economías domésticas endeudadas. Tocadas muchas de ellas, además, por el paro creciente, resultado de las dificultades empresariales ante los aumentos de costes y la caída de la productividad. No es de extrañar que los impagos alcanzaran al sistema financiero, provocando su deterioro, dando la impresión de que el origen de los problemas se encontraba en el mismo. Como Reinhart y Rogoff (2008) recuerdan, la caída de las tasas de crecimiento real suelen preceder a la aparición de las crisis financieras, aportando una variada información estadística al respecto. Aun cuando la situación financiera repercuta, a su vez, sobre los mercados de bienes y servicios, agravando aún más la situación (ver Gertler, Kiyotaki y Queralt, 2010, p. 2).

La falta de liquidez sobrevenida, la pérdida de valor de unos activos de cobro dudoso o imposible, la desconfianza introducida en las prácticas bancarias, la pérdida de credibilidad y solvencia..., provocaron un endurecimiento aún mayor de las condiciones del crédito, y una contracción del mismo. La caída subsiguiente del consumo y de la inversión presionaba, como en los años treinta del siglo anterior, sobre los precios a la baja, haciendo temer la inminencia de un proceso de deflación, a partir de julio de 2008. La bajada de los tipos de interés de referencia, ante tal panorama, ciertamente, llegaba tarde, cuando el daño sustancial sobre las economías ya se había producido. Sin embargo, la persistencia de dificultades en el lado de la oferta (aunque, de momento, los precios del petróleo comenzaran a descender, contribuyendo a esa sensación deflacionista), presionan sobre los precios al alza, contrarrestando el movimiento anterior, dando la impresión final de estar estabilizados, con sólo pequeñas oscilaciones de corta duración en un sentido y otro (según el peso relativo en cada momento de unos u otros componentes), que confunden a los observadores. La combinación de ambos movimientos se traduce, sin embargo, en un mayor aumento del paro y en una contracción reforzada de la producción.

Ante tal panorama, no es de extrañar el aumento del gasto público (ya de por sí afectado por los compromisos del pasado reciente y los rescates de las entidades bancarias), reduciéndose al mismo tiempo la recaudación fiscal como consecuencia de la caída de rentas y beneficios. Aumentando, en consecuencia, los déficits de los Estados, socavando su credibilidad y solvencia; sobre todo en aquellas economías más débiles, aquejadas por problemas más graves, como en el caso de la española.

Pensar en corregir tales déficits mediante reducciones arbitrarias de gasto y aumentos impositivos, como se está haciendo en la actualidad, lejos de solucionar los problemas, sólo puede derivar en un aumento de las dificultades colectivas (al reducirse, por una parte, la demanda agregada, y aumentarse, por otra, los costes de la producción, motivados por el deterioro del capital fijo social y la mayor presión fiscal), sin que, por todo ello, puedan arreglarse las finanzas estatales. Al menos, 
hasta que el hundimiento de la economía sea tal, que convierta en naturales la austeridad y el sacrificio. Como hemos hecho más arriba, recordando las palabras de Keynes, escritas en el contexto de la Gran Depresión como prevención ante determinadas propuestas de la época, y adaptándolas al caso, podríamos decir que tal política, "lejos de ser un medio de disminuir los problemas, es más bien un método de distribuir niveladamente los problemas existentes, a costa de aumentarlos algo más" (ver Keynes [1933] 1973, p. 102).

\section{CONCLUSIONES}

A la vista de todo lo considerado, se desprende, en primer lugar, la necesidad de ser particularmente sensibles tanto al lado de la oferta como al de la demanda, para poder interpretar de modo correcto el comportamiento cíclico de la economía y poder manejarlo en beneficio de la colectividad. El particular juego de equilibrios entre los diferentes componentes puede hacer bascular la evolución económica en direcciones distintas, que afectan a problemas como el empleo, la producción o los precios. Debemos, por tanto, estar en condiciones de prevenir anticipadamente la marcha de los acontecimientos para adoptar las disposiciones adecuadas y evitar agravar los problemas, estableciendo con claridad en qué lado se encuentra el origen de los mismos, en cada caso, y como ello puede afectar al comportamiento general, teniendo en cuenta las respuestas previsibles de las variables situadas en uno y otro lado. En este sentido, es imprescindible superar la tradicional dicotomía entre modelos de oferta y demanda, $y$, por extensión, modelos microeconómicos y macroeconómicos, adoptando una perspectiva integrada.

Asimismo, resulta del mayor interés incorporar en el estudio del comportamiento cíclico no sólo el papel del mercado, sino, además, las acciones y reacciones públicas, e, incluso, de las entidades no lucrativas; así como ampliar nuestra percepción del comportamiento económico más allá de las estrechas perspectivas del homo oeconomicus, definido de acuerdo con una racionalidad unidimensional, enriqueciéndola con algunas otras características de la especie humana (como la codicia y la solidaridad), que también influyen en el devenir económico.

De acuerdo con los planteamientos señalados, parece razonable pensar que la superación de las actuales dificultades económicas requiere del empleo de políticas de amplio espectro, capaces de afectar simultáneamente a ambos lados, de la oferta y de la demanda, como serían las orientadas a reducir costes fiscales y financieros tanto para las empresas como para los particulares; las que persigan impulsar y aprovechar las potencialidades del sector no lucrativo; las que busquen no tanto reducir el gasto público, como mejorar la eficacia, eficiencia y efectividad del mismo, seleccionando con extremo rigor los destinos a que debe ser aplicado, en función de su capacidad de arrastre, su incidencia sobre la productividad, o su capacidad dinamizadora de la creatividad y la cohesión social, eliminando las partidas menos apropiadas para todo ello. 


\section{REFERENCIAS BIBLIOGRÁFICAS}

ARIAS, X. C. (2009): La crisis de 2008 y la naturaleza de la política económica. Serie Documentos de Trabajo, 4-2009. Alcalá de Henares: Instituto Universitario de Análisis Económico y Social.

BALL, G.W. (1980): “Una sobredosis de economistas”. El País, 29-4, p. 56.

BAECK, L. (1994): The Mediterraneam Tradition in Economic Thought. Londres y N. York: Routledge.

ESTAPÉ, F. (1993): Ibn Jaldún o el precursor. Barcelona: Real Academia de Buenas Letras de Barcelona y Publicacions de la Universitats Autónoma de Barcelona.

ESTAPÉ, F. (2000): Ibn Jaldún: un economista del siglo XIV. En: FUENTES QUINTANA, E. (dir.): Economía y economistas españoles, 2: De los orígenes al mercantilismo, pp. 75-97. Barcelona: Galaxia Gutenberg-Círculo de Lectores.

GARCÍA LIZANA, A. y CHAMIZO, P.J. (2002): "Las claves de la revolución keynesiana y su vigencia actual. Una aproximación desde el análisis lingüístico", Estudios de Economía Aplicada, 20-1, pp. 111-135.

GARCÍA LIZANA, A. y MORENO JIMÉNEZ, J.M. (2008): "Economía y democracia en la sociedad del conocimiento". Estudios de Economía Aplicada, 26-2, pp. 181-212.

GERTLER, M.; KIYOTAKI, N. y QUERALT, A. (2010): Financial Crisis, Bank Risk Exposure and Goverment Financial Policy. En: htpp: // www.hec.unil.ch/cocuments/seminars/deep/ 312.pdf. (Último acceso: octubre de 2010).

GRICE-HUTCHINSON, M. (1995): Ensayos sobre el pensamiento económico en España. Madrid: Alianza.

HERRERA GÓMEZ, M. y CASTÓN BOYER, P. (2003): Las políticas sociales en las sociedades complejas. Barcelona: Ariel.

IBN JALDÚN AL-HADRAMI, A.I.M. [1377] (1977): Introducción a la Historia Universal. México: F.C.E.

IIZUKA, I. (s/f): La Escuela de Salamanca en los Primeros Tiempos de la Historia de la Teoría Monetaria. Tokio: Edición policopiada,

KEYNES, J.M. [1933] (1973): "El camino hacia la prosperidad". En DOMíNGUEZ DEL BRÍO, F. (dir.): Política Fiscal en Acción; pp. 87-123. Madrid: I.E.F.

KEYNES, J.M. [1936] (1983): The General Theory of Employment, Interest and Money. Cambridge: Macmillan y Cambridge U. P.

LAFFER, A.B. y SEYMOUR, J.P. (Ed.) (1979): The Economics of the Tax Revolt. A Reader. Nueva York: Harcourt Brace Jovanovich, Inc..

MONZÓN, J.L. (coord.) (2008): "Monográfico: Economía Social: El tercer sector en un nuevo escenario". Estudios de Economía Aplicada, 26-1.

NAUDÉ, W. (2010): "New Challenges for Industrial Policy". Working Paper UNU-WIDER, 107. Helsinki: United Nations University.

REINHART, C. y ROGOFF, K.S. (2008): "Is the 2007 U.S. Sub-Prime Financial Crisis So Different? An International Historical Comparison". American Economic Review, 98, pp. 339-344.

SCHUMPETER, J.A. (1954): History of Economic Analysis. N. York: Oxford P.

SKIDELSKY, R. (2009): La irrealidad del ciclo económico "real". En: www.projectsyndicate.org. Traducción de Kena Nequiz. (Último acceso: octubre de 2010).

TAMAMES, R. (2009): Para salir de la crisis global. Análisis y soluciones. Madrid: EDAF.

TRÍAS DE BES, F. (2009): El hombre que cambió su casa por un tulipán. Madrid: Ediciones Temas de Hoy. 
